\title{
Finansal Teknoloji Şirketleri ve Geleceğin Bankacılığı: Açık Bankacılık
}

\author{
Doğuş Bilgel $^{1 *}$, Besim Aksoy $^{2}$ \\ ${ }^{1}$ Finberg, Maslak, İstanbul, Türkiye (ORCID: 0000-0003-0026-8675) \\ 2 Fibabanka Ar-Ge Merkezi, Şişli, İstanbul, Türkiye (ORCID: 0000-0003-2634-0727)
}

(İlk Geliş Tarihi 13 Kasım 2019 ve Kabul Tarihi 31 Aralık 2019)

(DOI: 10.31590/ejosat.646196)

\section{$\ddot{O} \mathbf{z}$}

Bankacılık ve finans sektöründe ürün gelişimine yönelik stratejik hedefler, küresel para piyasalarını şekillendiren ve bu sürece bağlı olarak yeni teknolojik gelişmeleri tetikleyen önemli unsurların ortaya çıkmasına neden olmaktadır. Açık bankacılık ve finansal teknoloji şirket modelleri, küresel para piyasalarının teknolojik olarak ortaya çıkardığı dönemsel ürünlerdir. Bu tür teknolojik gelişimlere uyum sağlanması ise, ülkelerin teknolojik altyapısına bağlı olarak bu ürünlerin uygulanmasını ve adaptasyon süreçlerini etkilemektedir. Bu süreçte, bankaların finansal teknoloji şirketleri ile ortak bir strateji çatısı altında bankaların uygulama programlama ara yüzleri gibi çeşitli altyapı hizmetlerini kullanmak suretiyle optimize edilip yeni ürünlerin ortaya çıkarılması sağlanabilir.

Bu çalışmada, Türkiye bankacılık sektörünün uygulama programlama ara yüzlerinin altyapı çerçevesinde finans teknoloji şirketleri ile olası strateji hedeflerinin tartı̧ılarak, elde edilebilecek yeni ürünlerin teknolojik gelişmeye olan katkısı değerlendirilmiştir.

Anahtar Kelimeler: Bankacılık, Açık bankacılık, Finans Teknoloji Şirketleri, Uygulama Programlama Ara yüzleri

\section{Financial Technology Companies and Future Banking: Open Banking}

\begin{abstract}
Strategic goals for product development in the banking and finance sectors lead to the emergence of important elements that shape the global money markets and trigger new technological developments related to this process. Open banking and financial technology company models are the periodical products of global money markets. Adapting to such technological developments affects the implementation and adaptation processes of these products depending on the technological infrastructure of the countries. In this process, it can be ensured that new products can be optimized by using various infrastructure services such as application programming interfaces of banks under the common strategy of banks with financial technology companies. In this study, Turkey in the framework of the banking sector infrastructure application programming interfaces discussion of possible strategies target the financial technology companies, contributed to the technological development of new products which have been evaluated can be obtained.
\end{abstract}

Keywords: Banking, Open Banking, Financial Technology Companies, Application Programming Interfaces

\section{Giriş}

Günümüzde teknolojinin her alanda hızla gelişmesiyle birlikte birçok iş kolunda olduğu gibi finans sektöründe de çağa ayak uydurma, dijitalleşme ve kaliteli hizmet verebilmek adına birçok atılım yapılması gerekliliği ortaya çıkmıştır (Devrim, 2007). Bu gibi teknolojik gelişmeleri yapmak ciddi maliyetler yaratması sebebiyle bankalar kendi bünyelerinde yapabilmeleri bazı mali çekinceler doğurmuştur (Tanyeri ve Fırat - 2005). Fintek; geleneksel bankacılık ve finans piyasası işlemlerinin yavaş, çok fazla prosedürü olan, karmaşık yapısından sıyrılarak hızlı ve efektif çözümler sunan, çağa ayak uyduran teknolojiler sunmayı hedeflemektedir.

Finansal teknoloji şirketleri günümüzde makine öğrenimi(machine learning), davranış analizi, veri merkezli pazarlama ve API(Application Programing Interface)'leri kullanarak yeni teknolojiler geliştirmekte ve finansal alanda varlıklarını açıkça hissettirmeye başlamıştır. Geçtiğimiz yıl dünya genelinde fintek alanında yapılan yatırım miktarı 22,5 milyar Amerikan Doları'nı bulmuştur. Ülkemizde ise e-ticaretin gelişmesi ve mobil bankacılığa duyulan ilginin artmasıyla birlikte büyük yatırımlar yapılmaya başlanmıştır (Kantarcı vd. 2017).

\footnotetext{
*Sorumlu Yazar: Finberg, Maslak, İstanbul, Türkiye, ORCID: 0000-0003-0026-8675, dogus.bilgel@finberg.com.tr
} 
Türkiye'deki Fintek Yatırımları

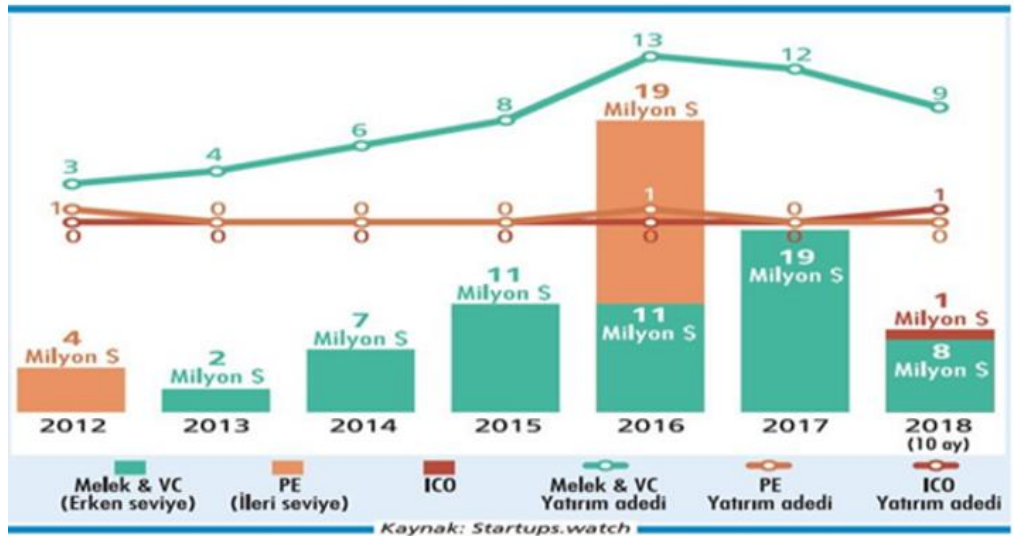

Şekil 1: Türkiye'deki Fintek Yatırtmları

Türkiye'de Fintek sayısı çoğalırken hizmet çeşitlilikleri de artmaya başlamıştır. 2019 Nisan itibariyle Türkiye'de 300'ün üzerinde fintek bulunmaktadır (Yağc1, 2018).

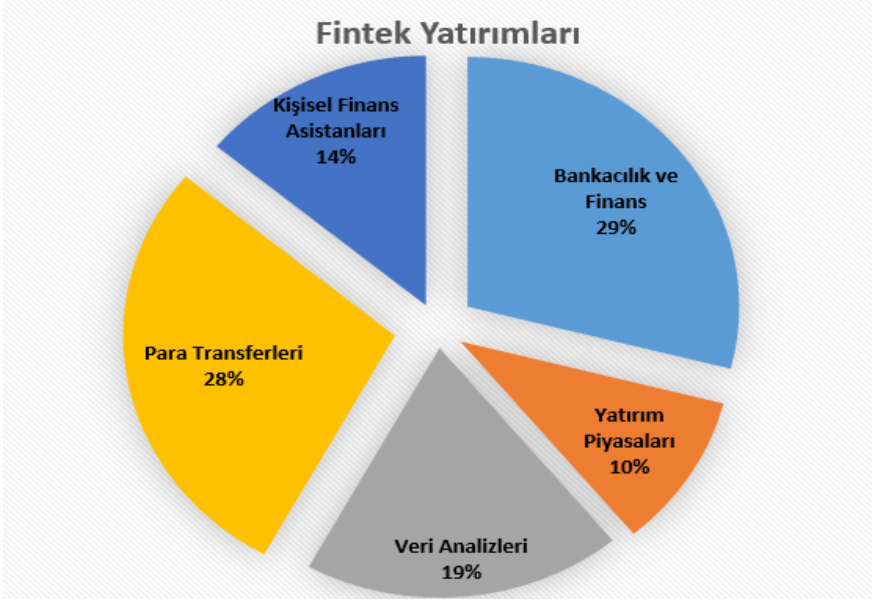

Şekil2: Türkiye'de ki Fintek Yatırımlarının Dă̆ılımı

Dünya genelinde geleceğin bankacılığı olarak nitelendirilen Açık Bankacılık (Open Banking) sistemi fintekler için, sağlam bir argüman niteliği kazanmış durumdadır. Öyle ki bankalar müşterilerinin kayıt altında tuttukları bilgilerini (ödeme tutarları, yapılan harcama bilgileri, düzenli ödenen faturalar vb. gibi bilgileri) müşteriler tarafindan verilecek izinler doğrultusunda finteklerin kullanımına açarak hizmet çeşitliliği yaratmaya başlamıştır (Ersoy, 2017). Ülkemizde ise belli başlı kurumlar dışında bu verileri API(Application Programing Interface)'ler aracılığıyla paylaşan kurum sayısı çok azdır. Bu kurumlara Tablo.3'te detaylı şekilde yer verilmiştir. Bankalar geçmişte bu kadar büyük veriyi toplamalarına rağmen işleyememeleri teknolojik gelişim ve dijital dönüşüm noktasında en büyük handikapları olmuştur. Bu durumlar göz önüne alındığında ülkemizde de açık bankacılık sisteminin işlem çeşitliliği, yeni hizmetler, zamandan tasarruf sağlayan, daha güvenilir bir hizmet anlayışı sağlaması bakımından ele alınması gerekliliği doğmuştur. Açık bankacılık servisleri ile bankalar müşterilerine daha düşük maliyetle daha kaliteli hizmet verme imkânı yakalamaktadırlar. Aynı zamanda farklı kanallardan müşteri kazanma ve cirolarını arttırma olanağı yakalayan bankalar, API marketlerini zenginleştirmeye devam etmektedir.

Fintek ve Açık Bankacılık anahtar kelimelerini akademik kaynaklarda araştırdığımızda ise bu alanda yazılan kaynakların azlığı, akademik bir araştırma ihtiyacını doğurmuştur. Haziran 2019 tarihi itibariyle Türkiye'deki kaynakları incelemek amacıyla, YÖK Tez Veritabanı ve Tübitak Ulakbim Veritabanı incelendiğinde "Fintek", "Açık Bankacılık" anahtar kelimeleri ile yapılan araştırmada sadece 2 adet yüksek lisans tezi (Göktepe, 2018), (Bilgiç, 2019) ve 2 adet makale (Taştan, 2019), (Menteş, 2019) tespit edilmiştir. Bu çalışmalar incelediğinde ise ağırlıklı olarak "Fintek" anahtar kelimesi üzerine yazılmış oldukları tespit edilmiştir. . Fintek alanında ve "Açık Bankacılık” anahtar kelimesi ile yazılan çalışmaların azlığı, bu alanlarda akademik çalışmalara ihtiyaç olduğu göstermektedir.

Uluslararası akademik kaynakları incelediğimizde ise "Fintek" ve "Açık Bankacılık" anahtar kelimelerine baktığımızda akademik yayınların büyük kısmının “Açık Bankacılık” üzerine incelemeye yoğunlaştığı görülmektedir. 


\begin{tabular}{|c|c|c|}
\hline & \multicolumn{2}{|c|}{ Anahtar Kelimeye Göre Toplam Yoyın/Sonuç Soyısı } \\
\hline Veritabanı & Fintech & Open Banking \\
\hline ScienceDirect & 384 & 40.234 \\
\hline Google Scholar & 27.600 & 65.100 \\
\hline Springer Link & 1.110 & 294 \\
\hline Jstor & 136 & 3.980 \\
\hline
\end{tabular}

Tablo 1: Fintek ve Açık Bankacılık Alanındaki Akademik Çalışmalar (Academic Research on Fintech and Open Banking)

\section{Materyal ve Metot}

\subsection{Finansal Teknoloji Şirketleri}

Teknolojinin gelişmesiyle iş alanlarının teknolojiyi kullanmadan gelişmesi imkânsız hale gelmişti. 2008 krizinden sonra bunu fark eden finans sektörü de Fintek sektörüyle teknolojiye ayak uydurmuştur. Finansal teknolojilerin kısaltması olan Fintek Bill Gates'in 1994’te söylediği meşhur bir sözü olan "Bankacılık gereklidir, bankalar değil.” (Beck,2001) düşüncesiyle ortaya çıkmıştır. Fintekler bankalara alternatif olmakla beraber aynı zamanda bankaların kendini geliştirmesine, müşterilerine yeni firsatlar sunmasına imkân vermektedir. Ayrıca müşterileriyle bire bir iletişimi azalan bankalar müşteri bağlılığı konusunda sorun yaşamaktadır. Bu tehdidi ortadan kaldırmak isteyen bankalar fintekler ile ortak çalışarak müşteriyle olan iletişimi koparmamak gibi bir hedef belirlemişlerdir.

Büyük teknoloji firmaları Amazon Pay, WhatsApp Pay, Apple Pay, Google Pay, Ali Pay de özel ödeme seçenekleri sunmasıyla bankalar da kendini yeni akımlara uyum sağlayarak geliştirmek zorunda kalmıştır. Çünkü bu büyük teknoloji firmaları sunacakları yeni ve kolay seçeneklerle dijitalleşen dünyada müşterilere çok daha rahat ulaşarak bankaların etkinliği azaltıp finans sektörünün yeni söz sahibi olmaya çalışmaktadırlar. Tekfin adı verilen bu şirketlerin sundukları ana fikir ise cüzdan uygulamalarıyla insanların artık yanlarında nakit para, kredi veya debit kartları bulunmadan sadece telefonlarıyla bütün ödeme, para transferleri ve parayla yapılabilecek her türlü etkinliği kolay ve hızlı ve zahmetsiz bir şekilde yapabilmesidir.

İnsanların her zaman en kolay yolu, nakit para yerine kredi veya debit kart kullanımı gibi, seçmesini firsat olarak bilen bu firmalar ulaşabildikleri müşteri sayısının da herhangi bir finans şirketine oranla çok daha fazla olmasıyla geleceğin bankacılığının sahibi olmak istemektedirler. Fintekler ve bankaların ortak ve ayrı çalışmaları ve tekfinlerin de ortaya çıkmasıyla bankacılık dijitalleşme yolunda önemli adımlar atmaya başladı. Kısaca fintekler müşterilerine dijital kanallar yardımıyla çeşitli firsatlar sunan yeni bir finans sektörüdür. Ödemeler, API sağlayıcıları, kripto para piyasası, fatura ödeme, borçlar ve kredi puanlaması, yazılım servisleri, muhasebe, kişisel finans ayarlamaları, para transferleri, kitlesel fon, kredi ve debit kartlar ve tahsilat servisleri finteklerin görev aldığı sektörler olarak sayılmaktadir.

Mobil ve dijital ödemeler ve para transferleri bu teknolojinin günümüzdeki en yaygın kullanım alanlarıdır. EY şirketinin yaptığ 1 araștırmaya göre bu kanalları kullanan müșteri oranı 2015 yılında \%18 iken 2017 yılında \%50'e yükselmiştir. Para transferlerinin ve ödemelerin \%83'ünü fintekler üzerinden gerçekleştiren Çin bu konuda dünyada baş1 çekmektedir. Çin’i \%72 ile Hindistan, \%60 ile Brezilya , \%59 ile Avustralya ve \%57 ile Büyük Britanya takip etmektedir. Ayrıca fintekler araciyla yapılan sigorta oranı \%8'den \%24'e, yatırım ve birikim oran $1 \% 8$ 'den \%20'ye, finansal planlama oranı $\% 8$ 'den \%10'a yükselmiştir. Aslında bu oranlar da finteklerin ileride ekonomide ne kadar önemli bir söz sahibi olacağının en önemli göstergelerinden biridir (EY,2017).

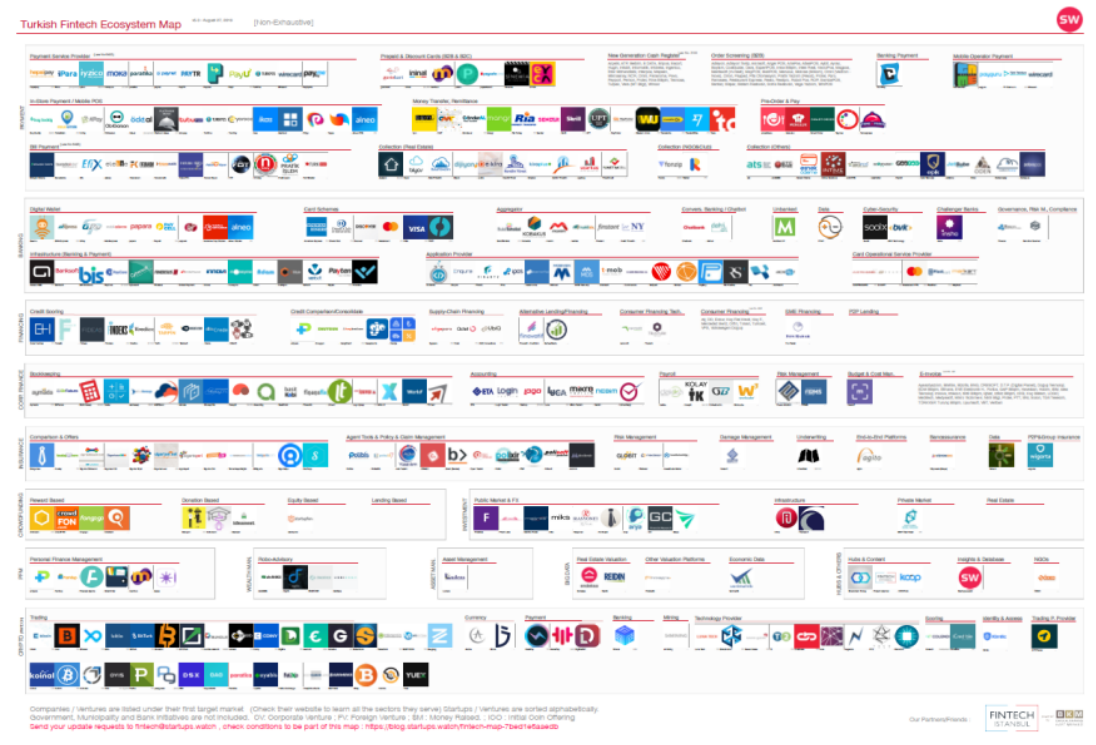

Şekil 3: Türkiye'deki Fintek Ekosistemi 
Bankaların çıkardıkları ürünler artıkça rekabet ortamının artmasına rağmen ürün fazlalığı müşteriler için farklı sorunları getirmektedir. Başta araştırmalara ayrılan süre olmak üzere müşterilerin kendileri için en doğru ürünü seçememesi gibi sorunlar bankalara olan güveni azaltmakta, müşterileri farklı yolları denemeye itmektedir. Bu duruma yeni bir cevap olarak da fintekler müşteriye özel ürünler sunarak bir sorunu daha çözme yoluna gitmişlerdir. Bu yolla pazar paylarını arttırmak isteyen fintekler ve bu firmalarla beraber çalışan bankalar müşteri memnuniyetini üst seviyede tutarak müşteri bağlılığını da arttırmayı hedeflemektedirler. Örneğin müşterinin hesabındaki para giriş çıkışlarını yapay zekâ aracıllğıyla analiz eden bu şirketlerin uygulamaları kişiye özel kredi, ödeme firsatları sunarak müşterilerinin finans kanalları olmakla birlikte finans alanında danışmanları olmaktadırlar. Aynı zamanda bu şirketler müşterilerinin geçmişlerine daha iyi ulaşabildiği için talep edilen ürünlere daha hızlı ve rahat bir şekilde ulaşabilecekler (Fintech İstanbul, 2018).

Finansal teknoloji şirketlerinin en önemli özelliklerinden biri ise kredilerin batma riskini en aza indirmesi olacaktır. Finansal krizlerle beraber Türkiye'de 2018 yılının sonu itibariyle batık kredi tutarı 92,2 milyar Türk Lirasına ulaşmış durumdadır (Sputnik news, 2018). Finansal krizle beraber insanlar kredilere yoğun bir ilgi göstermektedirler. Ancak geleneksel yöntemlerle verilen tüzel ve bireysel kredilerde risk analizi kişi bazlı yapıldığı için verimli sonuç almak çok zor olmaktadır. Finteklerin getirdiği yenilik ise bu risk analizlerini yapay zekâlara yaptırmaktır. Kredi başvurusu yapan kişinin risk durumu, bulunduğu sektördeki yeri, sektörün risk durumu ve buna benzer kredi için en önemli bilgileri analiz eden çeşitli yazılım programları bu bilgiler ışı̆̆ında kredi başvurusunda bulunan tüzel veya gerçek kişilerin kredi risk skorunu çıkarmaktadır. Bu skora göre kredi kullandırımı yapacak olan fintekler insan hatasını en aza indirerek batık kredi miktarını en aza indirmeyi hedeflemektedirler (BM Magazine, 2017).

Finansal teknoloji şirketleri ve geleceğin dijital bankacılı̆̆ her ne kadar şu anda çok hızlı bir büyüme gösterseler de yaptıkları bazı hatalar yüzünde hala beklenen seviyeye ulaşabilmiş değiller. Bu durumun birçok sebebi vardır. İlk sebep olarak teknolojiyle finans sektörü arasındaki büyük farkı sayabiliriz. Günümüzde teknoloji firmaları çok hızlı büyüyen ve hedeflerine hızlı ulaşan firmalardır. Ancak finans sektörü ise teknoloji firmalarının tam tersine yavaş değişkenlik gösteren geleneklerine bağlı bir sektördür. Dolayısıyla bu iki sektörün birleşmesinde büyük bir çelişki ortaya çıkmaktadır. Bu çelişki de fintek sektörüne yatırım yapacak firmaları geri adım atmaya itmektedir. Bir diğer sorun ise bu sektörün insanları kısa vadeli plana zorlamasıdır. Yatırımcıların finteklerden beklentileri çok büyük olduğu için geri dönüşünün çok hızlı olmasını beklemektedirler. Bu da fintekleri kısa vadeli plan yapmaya zorlamaktadır. Yapılan yatırımlar yeniliğe ve geliştirmeye harcanmak yerine kısa vadede para getirecek alanlara yapılmakta ve sektörün ilerlemesine engel teşkil etmektedir. En önemli problem ise finans sektöründeki büyük ve güçlü şirketlerin değişimi istememesidir. Alanındaki en büyük bankalar ve firmalar her ne kadar fintek sektörünün içine girse de bu sektörün büyümesi onların pazar payları açısından büyük tehlike arz etmektedir. Teknolojinin bu kadar ilerlediği bir ortamda Apple Pay, Google Pay, Ali Pay, WhatsApp Pay, Amazon Pay gibi tekfinlerin finans sektörüne çok güçlü bir şekilde girmesi finans şirketleri korkutmuş durumdadır. Çünkü bugüne kadar daha muhafazakâr bir şekilde ilerleyen bir sektör bu ani değişiklikle çok farklı pazarlara açılmaktadır. Bu değişiklik büyük finans şirketlerini ellerindeki gücü kaybetme ihtimaliyle karşı karşıya bırakmıştı. Bundan dolayı büyük finans kuruluşları fintek fikrinin uygulanmasını geciktirmek için büyük uğraşlar vermektedirler. Ve son olarak fintekler finans sektörünün yasal zorunluluklarına uymakta zorlanmaktadırlar. Kanunlar tarafında çok kesin bir şekilde korunan haklar, veri mahremiyeti gibi konular yüzünden fintekler yazılımlarını sürekli değiş̧irmek ve düzenlemek zorunda kalmaktadırlar. Bu durum da gelişimlerine engel teşkil etmektedir. Sonuç olarak fintekler teknolojiyi kullanarak finansal işlemlerini gerçekleştirerek işlemleri kolay ve hızlı bir şekilde gerçekleştirse de aynı zamanda çok büyük zorluklarla da karşı karşıya kalmış durumdadırlar (Myers, 2017; Vardanian, 2018; Fintechnews Singapore, 2019).

\subsection{Açık Bankacılık ve Ödeme Hizmetleri Yönergesi (Open Banking and Payment Services Directive)}

Açık bankacılık bankaların elindeki veriyi paylaşması yasal gereklilikler çerçevesinde paylaşmasıdır. Avrupa Birliği'nin onayladığı PSD2'ye (Ödeme Hizmetleri Direktifi 2) göre Avrupa'daki bankalar müşteri onaylı verilerini müşterilerine ve diğer kullanıcılar açmak zorundalar. Kanal bazlı açılan bu veriler Application Programming Interface (API) yani Uygulama Programlama Arayüzü adı verilen uygulamalarla halka açık hale geleceklerdir. Bu uygulamaların asıl amacı uygulamalar birbirlerinin uygulamaları üzerinden kendi uygulamalarında olmayan özellikleri kullanmasıdır. Finans sektöründe bu uygulamalar veri paylaşımı için de kullanılmaktadır. Bu veri paylaşımı sayesinde bankalar, fintekler, tekfinler ve diğer finans kuruluşları beraber hareket ederek müşterine en uygun ürünü ve hizmeti sunmayı hedeflemişlerdir (InfrasoftTech, 2018). Dünya üzerinde 24 Aralık 2018 tarihine kadar 428 banka API'lerini kullanıcılarına açmış durumdadır (Programmable Web, 2018). Bu bankalar başlıca; BBVA, HSBC, Barclays, Danske Bank, Deutsche Bank, Capital One ve ASB Bank'tır. Türkiye'de ise Garanti, Yapı Kredi, Kuveyt Türk, İş Bankası ve Denizbank API'lerinin bir kısmını açmışlardır. Bankalar kendi stratejilerine göre farklı ürünlerin API'lerini açmışlardır. Aşağıdaki tabloda göründüğü gibi her bankanın izlediği yol farklıdır. Bu yol aracılı̆̆ıyla da müşterilerine en iyi hizmeti vermeyi amaçlamışlardır. 


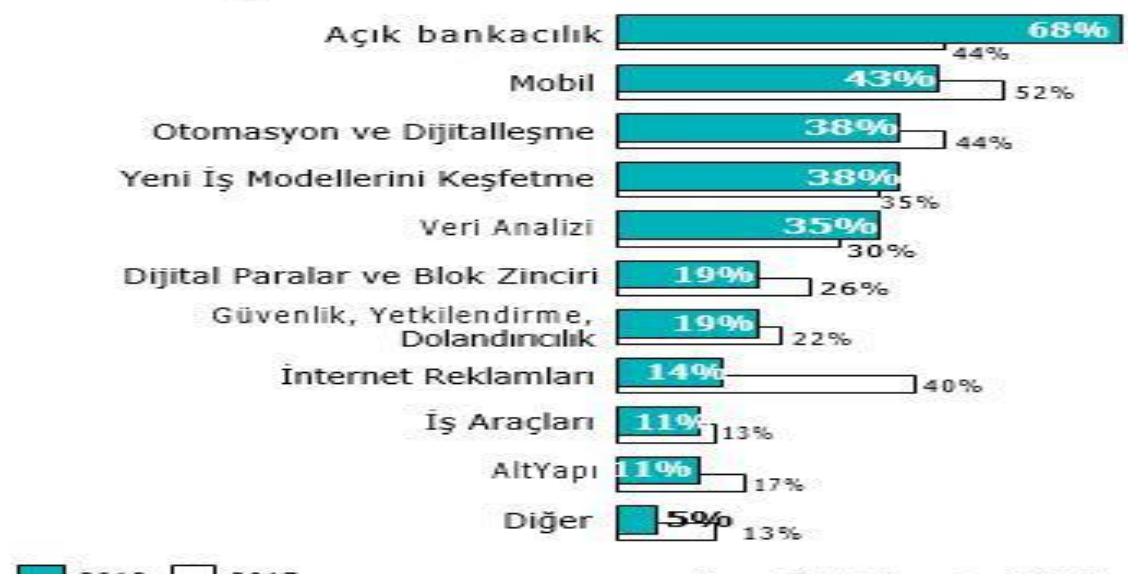

Tablo 2:MagnaCarta Fintek Araştırması

\begin{tabular}{|c|c|c|c|c|c|}
\hline API'ler/Bankalar & İş Bankası & Yapı Kredi & Garanti & KuveytTürk & Denizbank \\
\hline Kredi & 6 & 3 & 1 & 6 & 37 \\
\hline Müşteriler & 3 & 6 & - & - & 15 \\
\hline Kurlar & 1 & 6 & - & - & 3 \\
\hline Hesaplar & 3 & 10 & - & 8 & 13 \\
\hline Bilgilendirme & 4 & 10 & - & 10 & 12 \\
\hline Ödemeler & 4 & 3 & - & 4 & 42 \\
\hline Kartlar & - & 4 & - & 12 & 8 \\
\hline Para Transferleri & 2 & 6 & 1 & 14 & - \\
\hline Bağışlar & - & - & - & 5 & 9 \\
\hline Test & - & 4 & - & - & 18 \\
\hline Fonlar & - & 1 & - & - & 7 \\
\hline Faktöring & - & - & - & - & - \\
\hline Güvenlik & 2 & - & 1 & - & 23 \\
\hline Sanal POS & - & - & - & 4 & 10 \\
\hline Diğer & 6 & 3 & 1 & & \\
\hline
\end{tabular}

\subsubsection{Açık Bankacılık İş Kolları}

Açık bankacılık ve geleneksel bankacılığın aynı anda var olmasıyla, farklı iş kolları ortaya çıkmıştır. Accenture'ın yaptığı araştırmaya göre bankalar iki farklı organizasyon olarak oluşmuş ve bu organizasyonlar içinde dört farklı dijital iş modelleri vardır. Bu modeller açık bankacılık ile geleneksel bankalar arası farklı uygulamalar, yatırımlar ve riskler almaktadır.

\subsubsection{Fayda Sağlayıcılar}

PSD2( Ödeme Sistemleri Yönetmeliği) yasalarının zorunlu kıldığı elindeki verileri asgari seviyede üçüncü partilerle paylaşan kuruluşlardır. $\mathrm{Bu}$ yolu uygulayan kuruluşlar PSD2 sayesinde uygulayabilecekleri yeni stratejileri denemektense geleneksel sistemle devam etmeye çalışmaktadırlar. Bunun sonucu olarak kendini bu şekilde tanımlayan bankalar işlem yapma hacimlerini ve önemli kazançlarını karşılığında hiçbir şey kazanmadan kaybetme riskiyle karşı karşıya kalmaktadırlar.

\subsubsection{Dijital İlişkileri Yönetenler}

API (Uygulama Programlama Ara yüzü) kullanımı ve birçok servisin tek bir çatı altında toplanması finans sektörünün eskisine göre çok daha farklı olmasını sağlamaktadır. Bu farklılıklarla birlikte mevcut müşterilerin finans hizmetlerinin kullanım oranını arttırırken, bundan önce standart finans kuruluşlarıyla çalışmayan kişileri finans sektörünün yeni müşterileri yapmaktadır. Özellikle küçük bankalar, üçüncü partilerin verilerine API'leri aracılığıyla ulaşarak müşteri deneyimlerini dijitalleştirme, bağlılıklarını arttırma 
ve pazardaki paylarını arttırmayı amaçlamaktadırlar. Ayrıca dış kaynaklı verileri ve sahip oldukları verileri birleştirerek bankalar daha kaliteli ve kişiye özel ürün ve kampanyalarını müşterilerine sunabilmektedirler. Bankaların bilgi servisleri de gelir elde etme konusunda doğrudan rol oynayabilir, yeni müşterilere kazandırabilir ve geleneksel banka servislerini yeni ürünlerle geliştirebilmektedirler. Bu yenilikler sayesinde banka hareketlerinin bir parçası olduğu ve müşteri deneyimleri ve ilişkileriyle ilgilenen yeni iş kolları da ortaya çıkmaktadır. Bu modeli kullanan bankaların yapması gereken de üçüncü parti ortaklarıyla beraber müşterileri paylaşmak veya bu yenilikçi uygulamaların önüne geçmek olmamalıdır.

\subsubsection{Açık Platform Oyuncuları}

Bankalar diğer kuruluşlardan kullandıkları API hizmetleriyle oluşturdukları servisleri bir sonraki kullanıcıya satabilmektedirler. Bankalar, ortaklarıyla beraber servislerinde yeni paketler sunabilirler veya ürünlerini ve servislerini farklı tip müşterilere yeni özellikler ekleyerek tekrar servis edebilmektedirler.

\subsubsection{Dijital Kategori Katilleri}

Bankaların iç kaynaklara API'lerini açması mevcut süreçlerini geliştirmekte ve maliyetlerini düşürmektedir. Bu API'ler sadece bankada kullanılan Web API'leridir. Bu API'leri kullanma hakkı iş anlaşmasına göre şirket içi geliştiricilerde ve ortaklardadır. Bu iç kaynaklara açılan API'ler bankaların daha hızlı hareket etmesini sağlarken, çeşitli yeni teknolojilerinin uyum sürecini hızlandırmaktadır. Geleneksel yöntemde iş yapmaya devam eden bankaların bilgi teknolojileri bölümünün yeni iş fikirlerini uygulamaya koyması 18 ila 24 ay arası sürebilirken; iç kaynaklara açılan API'leri kullanarak yeni iş fikirlerini, örneğin yeni telefon uygulamaları ve kanal uygulamaları, sunmaya çalışan bankalarda bu süre birkaç haftaya kadar düşebilmektedir.

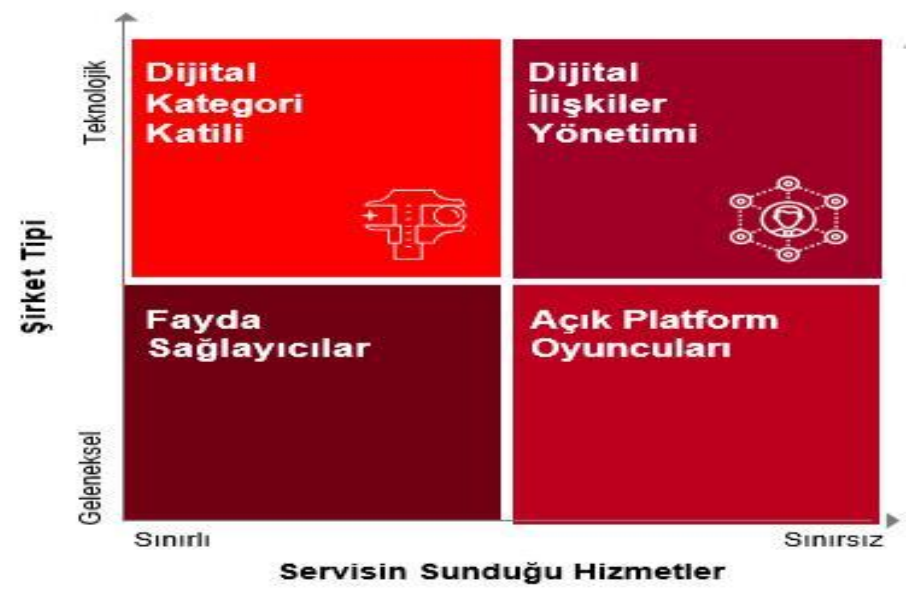

Şekil 4:Açık Bankacılık Iş̧ Kolları

\subsubsection{Açık Bankacılıktan Fayda Sağlayan İş Modelleri}

KPMG raporlarına göre şu anda geleneksel banka yöntemleriyle çalışan iş modellerinin bazıları açık bankacılık kısmında da aktif olarak çalışarak kendi faydaları için yeni modeller oluşturmuşlardır.

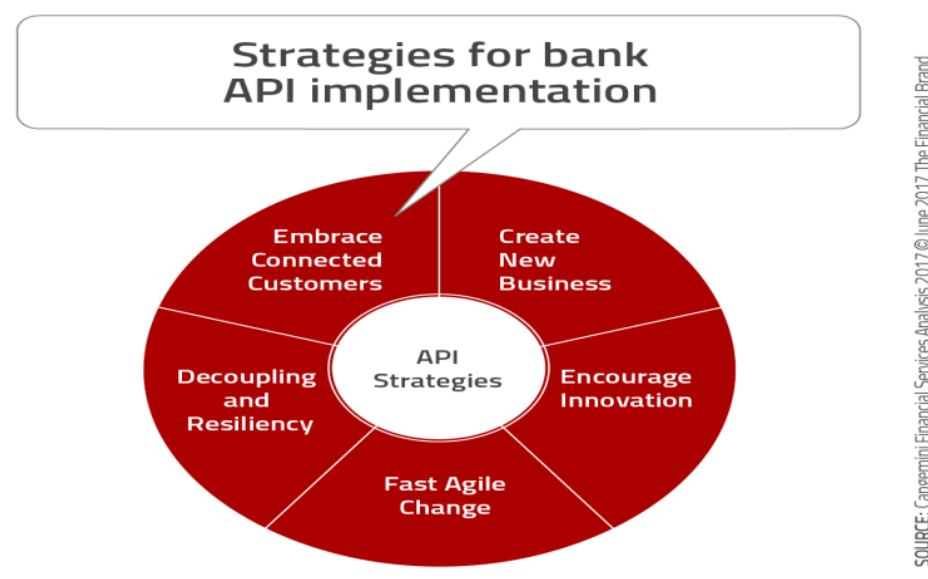

Tablo 4: Banka API Uygulaması için Stratejiler 


\subsubsection{Proje Sağlayıcılar}

Xero, Sage, Intuit gibi fintekler, Dijital bankalar ve bulut hesap sağlayıcılar için açık bankacılığın proje aşamasında birçok farklı firsat bulunmaktadır. Bu şirketlerin ana odak noktası müşterilerinin fatura ve diğer ödemeleri için üst düzey hizmet sağlamaktır. Kobilerin verilerine ulaşarak para ve zaman konusunda verimliliği arttıran hizmetler sunmaktadırlar.

\subsubsection{Ekosistem ve Uygulama Mağazaları Oyuncuları}

Bu hizmet sayesinde kobiler ihtiyacı olan bütün hizmetlere tek bir uygulama üzerinden ulaşabilmektedirler. Kobiler uygulamaları indirip sadece kullanacakları hizmetleri tek seferde kontrol edip işlemlerini yapabilmektedirler. Bu modelin kullanılmasının en büyük amacı, finans sektöründeki şirketlerin müşterilerinin isteklerini ve beklentilerini tam anlamıyla karşılamakta zorlanmasıdır. Ve bundan dolayı hız, güven ve verimlilik konusunda zorluk çekmeleridir. Bu model sayesinde bu sorunlar çözülmesi beklenmektedir. Starling Marketplace bu ekosistem yaklaşımının en iyi örneklerinden biridir.

\subsubsection{Bayilik Genişletme Yöntemi}

Bayilikle çalışan firmalar açık bankacılığı kullanarak bayiliklerine yeni ödeme servislerini sunmaktadırlar. Örneğin, bağımsız bayilikler şu an ödedikleri satıcılara ödedikleri ücretleri azaltmakta büyük zorluk çekmektedirler.

Bir diğer modelde ise mevcut ödeme servislerini genişleterek kobi müşterilerine ve tedarik zincirindeki kuruluşlarına ödeme kolaylığı sağlamaktadır.

\subsubsection{Akış Canavarları}

Akış canavarları bilançoları yöneten kuruluşlardır. Açık bankacılık zincirinin büyük bir destekçisi olan bu kuruluşlar bütün sorumluluk ve varlıkları elinde tuttuğundan açık bankacılık oyuncuları için düzenlemeleri yapabilmektedirler. Akış canavarlarının banka işlemlerini yapabilmek için yetkileri vardır. Güçlü bir kredi notuna sahip olan bu şirketler, başarılı bir sermaye ve likidite sahibidirler.

\subsubsection{5. Ürün Yöneticileri}

Bazı finansal servisler ürün yöneticisi olmayı tercih etmişlerdir. Bu kuruluşlar ürünlerini şu anda var olan diğer platformlardan sunmaktadırlar. Örneğin bazı genel sigorta şirketleri risk iştahı konusunda uzmanlaşmış ve bu konuda ürünlerini sigorta şirketlerine sunmaktadırlar.

\subsubsection{Sektör Yöneticileri}

Ürün yöneticileri gibi sektör yöneticileri de bazı spasifik sektörlerde uzmanlaşmışlardır. Örneğin Manufacturers Bankası üretim alanındaki kobilerin aktivitelerinin \%15'ne odaklanmış ve bu konuda ürünler sunmaktadır. Banka kobilerin uzun dönemli yatırımlarına destek olur ve başarılı bir şekilde büyümelerini sağlamaktadır.

Kobiler

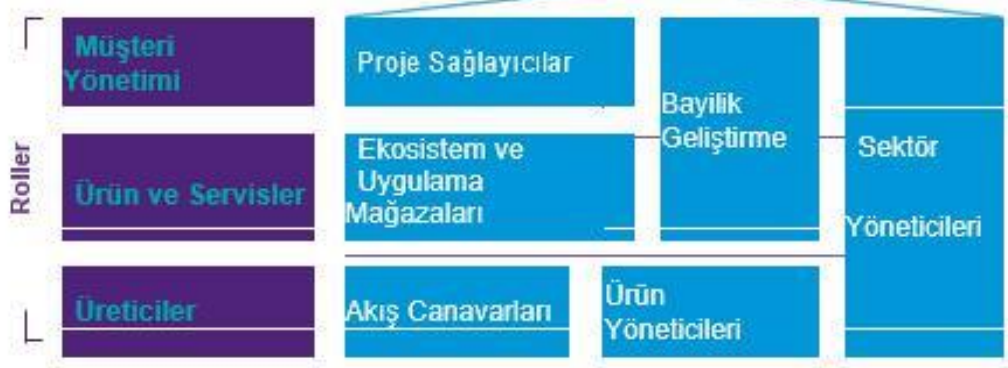

Şekil 5:Açık Bankacılıktan Yarar Sağlayan İş Modelleri

Teknolojinin gelişmesiyle birlikte bankalar da uyum sürecine girmiştir. Sadece açık bankacılık değil bir çok farklı yolla bankalar teknolojiyi geleneksel yöntemlere entegre etmişlerdir. Efma-Infosys Finacle'ın yaptığı dijital bankalar raporuna göre bankalar başlıca 11 teknolojik uygulamayı bankalarına uygulamışlardır. Aşă̆ı̆daki tabloda da görüldüğü gibi başlıca açık bankacılık (Open API), yapay zekâ (Artificial Intelligence), konuşmaya dayalı ara yüz (Chatbox) gibi uygulamaların geleneksel bankacıllğın işlemlerine etkisi artmıştır. 


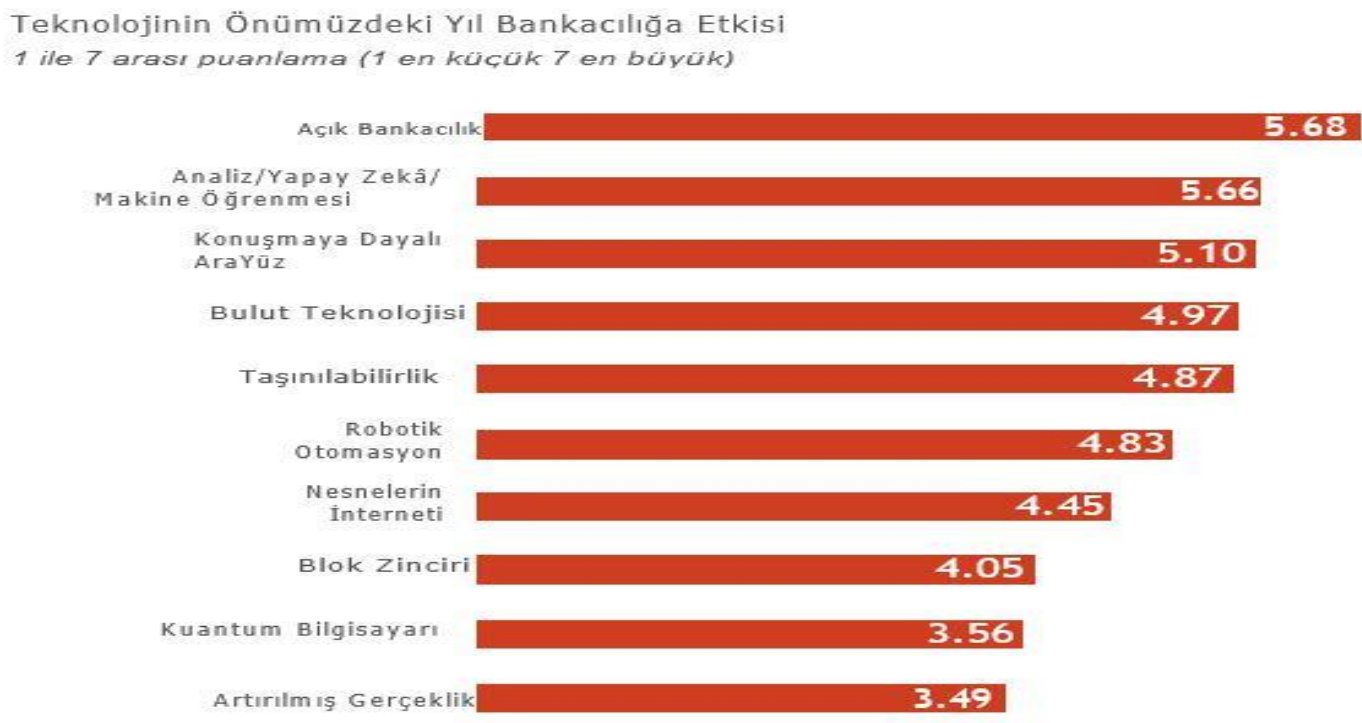

Source: Efma-Infosys Finacle Digital Banking Report Survey 2018

Tablo5: Teknolojinin Gelecek Yıl Bankacıliğa Etkisi

\section{Sonuç ve Tartışma}

Bankacılık ve finans sektörü ile birlikte bu ekosistemin içinde kalan veya bir şekilde ortak bir kesişim kümesi bulunan tüm alanlar, günden güne birbirine daha fazla yakınlaşarak yeni bir dünyanın kapılarını açmaktadır. Açık Bankacılığın bir strateji veya zorunluluk olmanın ötesine geçerek sektörün geleceğini şekillendireceği söylenebilinmektedir. Bankaların son dönemlerde yaptı̆̆ı fintek yatırımlarının meyvelerini almaya başlaması ve olumlu geri bildirimler alınması da sektörün gelecekte diğer sektörlerden bir adım değil birkaç adım önde olacağını göstermektedir.

Yapılan araştırmalar gösteriyor ki ülke olarak verinin doğru kullanımı, süreçlerin doğru yönetilmesi, fintek işbirliklerine olan ilginin artması ve en önemlisi müşteri ihtiyacının iyi analiz edilmesi noktasında işler yapmaktayız. API bankacılı̆̆ konusunda ülkemizde her ne kadar bankaların API Marketleri sınırlı sayıda olsa da artış eğiliminde olduğunu söylemek mümkündür. Bankalar dışarı API yayınlamakta çekince duysalar da artan rekabetçi ortamda bunun gerekliliği hususunda bu motivasyonu yakalayacaklardır. Burada en büyük faydayı tüketicilerin göreceği; daha düşük fiyatlardan, daha fazla ürün seçeneklerine ulaşma imkânı sağlayacağı su götürmez bir gerçektir. PSD2 kapsamında yurt dışı örneklerinde olduğu gibi bankalar ve finans kurumlarına API'lerini yayınlama zorunluluğu getirmek doğru olacaktır. PSD2 kuralları özellikle Avrupa'da bu kümeye yeni giriş yapacak girişimcilere gerekli motivasyonu vermektedir. Buna benzer bir düzenlemenin de rekabet eşiğimizin artması adına ülkemizde de yapılması gerekmektedir.

Ülkemizde özellikle sektörel bazda piyasa baskısını en yoğun hisseden sektörlerin başında gelen bankacılık ve finans sektörü açısından fintek kültürünü benimsemelerinin ve API'lerini dış kullanıma açmalarının onların lehine olacağı şüphesiz bir gerçektir. Bu konuda hem Avrupa'daki hem de ülkemizdeki örnekleri dikkate alarak adım atmaları teşvik edilmelidir. Ülkemizde akademik ve regülatif bakımdan çalışmalar başlatılarak bu alanda ülke olarak daha iyi bir konuma ve saygıya sahip olabiliriz.

\section{Terminoloji}

API: Application Programing Interface / Uygulama Programlama Arayüzü

Fintek: Finansal Teknoloji Şirketleri

PSD2: Ödeme Hizmetleri Direktifi 2

CHATBOT: Konuşmaya Dayalı Arayüz

AI: Artificial İntelligence / Yapay Zekâ

YÖK: Yüksek Öğretim Kurumu

TÜBITAK: Türkiye Bilimsel ve Teknik Araştırma Kurumu

ULAKBİM: Ulusal Akademik Ağ ve Bilgi Merkezi

\section{Kaynakça}

F DEVRIM, Aİ ÖZPENÇE - 4. KOBİ'ler ve Verimlilik Kongresi - openaccess.iku.edu.tr https://s3.amazonaws.com/academia.edu.documents/55851881/07-MUSTAFA_YAGCI.pdf?response-contentdisposition=inline \%3B\%20filename\%3DYukselen_Finansal_Teknolojilerin_Ekonomi.pdf\&X-Amz-Algorithm http://www.eticaretraporu.org/wp-content/uploads/2017/04/TUSIAD_E-Ticaret_Raporu_2017.pdf

https://developer.kuveytturk.com.tr/ https://apiportal.yapikredi.com.tr/ 
https://api.intertech.com.tr https://developers.garanti.com.tr/ https://developer.isbank.com.tr https://fintechistanbul.org/02/02/2019/wp-content/uploads/2019/03/Fintek-Makale1.pdf https://fintechistanbul.org/2019/08/05/acik-bankacilik-finans-sektorunu-yeniden-sekillendiriyor/ https://fintechistanbul.org/09/09/2019/turkiye-banka-fintech-is-birlikleri-haritasi-beta-1-0/ https://thefinancialbrand.com/65975/01/09/2019/open-banking-api-fintech-partnerships/

https:/www2.deloitte.com/01/06/2019/content/dam/Deloitte/global/Documents/About-Deloitte/central-europe/ce-digital-bankingmaturity-study-emea.pdf?nc=1

ProgrammableWeb. (2019). Banking APIs. [online] Available at: https://www.programmableweb.com/category/banking/api

Anon, (2019). [online] Available at: http:/www.infrasofttech.com/blog/open-banking-apis-changing-landscape-banking

Forbes.com. (2017). 3 Reasons Fintech Is Failing. [online] Available at: https://www.forbes.com/sites/chrismyers/2017/02/07/3reasons-why-fintech-is-failing/

Medium. (2018). Why fintech startups fail. 5 mistakes and conclusions. [online] Available at: https://medium.com/swlh/why-fintechstartups-fail-5-mistakes-and-conclusions-b77e1bde23d2

Singapore, F. (2018). 8 Reasons Why Fintech Startups Fail. [online] Fintech Singapore. Available at: http://fintechnews.sg/20296/fintech/reasons-why-fintech-startups-fail/

Bmmagazine.com, V. (2017). The importance of FinTech in finance. [online] Business Matters. Available at: https://www.bmmagazine.co.uk/finance/importance-fintech-finance/

https://www.sputniknews.com. (2018). Batık kredi oran1 8 y1lın zirvesinde. [online] Available

at: https://tr.sputniknews.com/ekonomi/201812271036825464-batik-kredi-orani-sekiz-yilin-zirvesinde/

Ey.com. (2017). [online] Available at: *https://www.ey.com/Publication/vwLUAssets/ey-fintech-adoption-index-2017/\$FILE/eyfintech-adoption-index-2017.pdf

Beck, H. NETNOMICS: Economic Research and Electronic Networking (2001) 3: 7.

Usta, A. (2018). Açık Bankacılık hakkında sorular ve cevapları. [online] FinTech İstanbul. *Available at: https:/fintechistanbul.org/2018/01/23/acik-bankacilik-hakkinda-sorular-ve-cevaplari/

2018, I. (2018). Innovation in Retail Banking 2018 - Digital Banking Report. [online] *Digital Banking Report.

Fintech.istanbul. (2018). [online] Available at: http://fintech.istanbul/en/wp-content/uploads/2016/06/Fintech-Ecosystem-Map-v4.1.pdf

MagnaCarta Communications. (2018). 2018 Fintech Disruptors Report, exclusively from *MagnaCarta. [online] Available at: https://www.magnacartacomms.com/2018-fintech-disruptors-report

KPMG (2018). 2018 Is Open Banking Open for Business, exclusively KPMG [online] Available at: https://assets.kpmg/content/dam/kpmg/uk/pdf/2018/11/is-open-banking-open-for-business.pdf

GÖKTEPE, Serkan.” Türkiye'deki Fintech girişimleri -Fintech girişimleri bankaların geleneksel kredi onay ve kredi verme süreçlerini nasıl değiştirecek?”. Yüksek Lisans Tezi, Bahçeşehir Üniversitesi, 2018

BİLGİÇ, Elif.” Dijital finansal ürün ve hizmetlerin büyümesi: Türkiye'de Fintech hizmet ve çözümlerinin genişlemesi üzerine bir araştırma." Yüksek Lisans Tezi, Bahçeșehir Üniversitesi, 2019

TAŞTAN, Selim.” Küresel Finansal Teknoloji Sektöründe Ortaya Çıkan Yeni Girişimlerin Ekonomik ve Teknolojik Belirleyicileri".Haliç Üniversitesi Sosyal Bilimleri Dergisi 2/1 (Ocak 2019):41-69

MENTEŞ, Ahmet.” Finansal Tabana Yayılma Aracı Olarak Finansal Teknoloji Şirketleri”. Sosyal Bilimler Araştırma Dergisi 8/1 (Ocak 2019: $168-175$ 